\title{
A SOCIAL WELFARE APPROACH TO REGIONAL CONVERGENCE
}

\author{
Mo-Yin Tam, Joseph Persky, Eric Schlaf*
}

\section{Introduction}

The regions of the United States are usually compared in terms of their per capita incomes. Questions of ranking and convergence are most often stated with respect to average income. Average income is of obvious importance, however, the general theory of social welfare emphasizes the significance of the entire distribution of income and not just its central tendency. The same per capita income has very different welfare implications depending on how unequally it is distributed.

The discussion of regional convergence has been carried out without attention to the question of regional income distributions. To a large extent this has reflected the importance attached to per capita income in models of national and regional growth. From such a vantage point, distribution is of secondary importance. Alternatively, some might argue that regional income distributions are not inherently meaningful and only the national income distribution has significance. This is a non-trival proposition. At this point we simply affirm our belief that mean incomes are a poor summary measure of regional welfare. Especially when mean incomes are similar, regions are best characterized by indexes sensitive to distribution as well as central tendency.

We wish to broaden the discussion of regional comparisons to include the entire regional income distribution. A region's level of equality as well as its average income should be considered. In this venture the literature of social welfare functions can be of considerable assistance. In particular, our approach is heavily in debt to those researchers who have emphasized the relation between these functions and measures of inequality (Atkinson, 1970, as generalized by Blackorby and Donaldson, 1978). Following Blackorby and Donaldson virtually any reasonable welfare function $\mathrm{W}$ can be represented as the product of mean income and a measure of equality:

$W=u E$

where $\mathrm{u}$ is mean income and $\mathrm{E}$ is a measure of equality standardized so that $\mathrm{E}=1$ when all individual incomes $\mathrm{y}_{\mathrm{i}}=\mathrm{u}$. W is a more reasonable index of a region's *University of Illinois at Chicago income distribution than $\mathrm{u}$ alone since it gives the shape of that distribution some weight. Therefore, we can address our concern with distribution by ranking regions vis a vis their level of social welfare. In this vein, it is important to consider not only the convergence of $\mathrm{u}$, but also the regional convergence of social welfare.

The problem, of course, is to pick a particular measure of social welfare and hence of equality. Notice that this same issue exists even in the simpler case of ranking by central tendency. As long as all incomes in a region are not equal, there is no uniquely superior measure. A ranking based on mean income will not in general agree with one based on medians or modes. Precisely because distributions can vary, one might observe convergence in the mean incomes and divergence in the medians.

One way to avoid the ethical dilemmas involved in choosing a social welfare function is to construct partial orderings that are consistent with a broad range of welfare functions. This is our first approach. The central idea is to build a partial ordering based on the notion of a generalized Lorenz curve. This curve is nothing more than the standard Lorenz curve income multiplied by the regional mean income (see Figure 1). Recent work by Shorrock (1983) and others has shown that comparing such curves can yield a partial ordering valid for a broad and intuitively appealing class of social welfare functions (see Section Ranking of Regional Welfare for details). Within this class are those social welfare functions associated with the Gini coefficient, Atkinson's indexes, and Theil's index. For this family of social welfare functions, generalized Lorenz dominance provides an ordering of regions. This ordering fails if the generalized Lorenz curves of any two regions intersect. When such intersections occur, the ordering is only partial.

In addition to such a partial ordering, we will calculate complete orderings based on several important social welfare functions, each of which corresponds to a well known measure of equality. All of these were derived by Blackorby and Donaldson (1978). The first welfare function we consider is based on the Gini coefficient. We also report values for three members of the Atkinson family. Finally we will look at a social welfare function based on Theil's entropy index. 
The goal of this paper is not just to produce static rankings. We also wish to draw conclusions concerning the extent to which regional social welfare has converged over time. In what follows we suggest a natural measure of convergence to apply to complete orderings generated by specific social welfare functions. For the partial orderings the issue is less easily resolved. How does one measure the degree of convergence in an incomplete ordering system? There is some doubt as to the precise meaning of the question, let alone its answer. Nevertheless we suggest an approach which seems useful, if painfully incomplete.

The next section describes the basic data sources and methodology used in the rest of the paper. This may reasonably be skipped by those familiar (or impatient) with income distribution data and manipulation. The third section presents the basic rankings (partial and complete) for 1980 for the nine U.S. Census regions. In the fourth section we develop the basic measures of proximity for inter-regional income distributions. The next section compares the values of the above measures in 1980 to those in 1950 and discusses the extent and quality of inter-regional convergence of social welfare in the United States.

\section{Methodology}

The basic data sources used in all the calculations presented below are the U.S. Census of Population for 1950 and 1980. For each region these censuses provide data on the distribution of families by regions over nine income classes. The 1950 classes break at $\$ 1000$, $\$ 2000, \$ 3000, \$ 4000, \$ 5000, \$ 6000$, $\$ 7000$, and $\$ 10,000$. For 1980 the breakpoints are $\$ 5000, \$ 7500$, $\$ 10,000, \$ 15,000, \$ 20,000 \$ 25,000, \$ 35,000$ and $\$ 50,000$. A complete income distribution was estimated for each of the nine census regions in 1950 and 1980 . This was done using the technique developed by the Census Bureau, Spiers (1977). For each interval a Pareto curve was fitted to the interval endpoints. This is a function of the following form:

\section{(Number of Families with Income $>y$ ) $=k y^{-2}$,}

where $\mathbf{k}$ is a constant, $\mathbf{y}$ is the level of family income and ( $-a)$ is an exponent. This formula was used for interpolation if the absolute value of the exponent was greater than one. The interpolation is at \$25 intervals in 1950 and $\$ 100$ intervals in 1980 . If the exponent was less than one a linear interpolation was applied. For the open ended interval, the Pareto curve for the immediately preceding interval was extrapolated to construct the upper tail of the distribution. For the
1950 distributions any families with incomes greater than $\$ 100,000$ were assigned this figure. In 1980 any families with incomes greater than $\$ 1,000,000$ were assigned this figure. The 1980 Census provided data on regional mean incomes calculated directly from the underlying distribution. In no case did the means calculated from estimated distributions differ from the true means by more than 1.25 per cent. An income distribution for the U.S. for each year was constructed by simply merging the estimated regional distributions. The mean for 1980 of this distribution was $\$ 22,988$ as compared to a true mean of $\$ 23,092$.

Armed with these income distributions, we constructed simple piecewise Lorenz curves estimating the cumulative income share for each decile of regional population. The generalized Lorenz curves are these curves multiplied by the mean.

The various measures of equality and social welfare used in this study were calculated from the detailed regional income distributions. The formulas for all indexes are given in appendix Table A-1. It should be noted that the welfare indexes can be viewed as equivalent incomes in the sense first discussed by Atkinson. Thus a given welfare level $W_{O}$ can be achieved by an economy with a mean income $u_{o}$ and equality index $\mathrm{E}_{\mathrm{O}}$ or the same level can be achieved with a mean income $\mathrm{u}_{1}=\mathrm{W}_{\mathrm{O}}$ and equality index $\mathrm{E}_{1}=1.0$. If every family had income $W_{O}$ then the social welfare would be just as high. Hence the expression equivalent income

A word should be said about the comparability of the 1950 and 1980 data. Like all Census income data, it is likely that family income in both years was underestimated. This bias was probably more severe in 1950 when the farm population was relatively larger. In addition, the Census Bureau has gotten more sophisticated in its canvassing techniques and its enumeration of transfer payments. On a somewhat different front, the Census Bureau made no effort in 1950 to assign non-respondents to a particular income category, while in 1980 such an effort was carried out. What biases this might introduce into the 1950 distribution (or even the 1980 distribution) is unknown.

Finally we have made no effort to adjust for price differences over either space or time. Especially important to our problem is the spatial variation. Currently we know of no set of regional indexes that extends back to 1950 . Moreover we have serious doubts concerning the applicability of the purchasing power approach to regional indexes in a national system as open as that of the United States. We intend in the future to address these issues more seriously. For the purpose of this paper, however, all figures are in terms 
of current dollars. The reader should notice that all of the equality indexes used in this study are invariant to a proportional shift in all incomes. Thus all results derived from these indexes are independent of general inflationary effects. Several writers have advocated absolute indexes of inequality on the grounds that a 30 per cent difference in incomes is considerably more important when mean incomes are low than when they are high (see Kolm, 1976). However, there is little agreement concerning which absolute standard to adopt. This is an important issue, but further work at the regional level should await a clearer consensus concerning how to construct such measures.

\section{Ranking of Regional Welfare}

In this section we are going to examine the welfare ranking of the nine Census regions in the year 1980. Here we assume that all the families are identical in all aspects except their income levels. In this case the welfare of each region can be reflected by two considerations, namely its mean income level and the degree of equality in its income distribution. It is clear that the level of welfare varies with the particular equality index used. Thus the welfare levels of the nine regions and hence the relative ranking of regional welfare depend on which welfare function is chosen.

Let us first consider a broad class of welfare functions which are Pigou-Dalton and non-decreasing. Pigou-Dalton implies that a transfer of income from a richer person to a poorer person in the region will improve welfare. Non-decreasing means that an increase in income of an individual in the group will either increase the welfare of the group or leave it unchanged. Shorrocks (1983) has shown that for any two income distributions, $y$ and $y^{1}, W(y)>W\left(y^{1}\right)$ for all $W$ in this class of welfare functions if and only if $\mathrm{GL}(y, p)>\mathrm{GL}\left(\mathrm{y}^{1}, \mathrm{p}\right)$ where $\mathrm{p}$ is the lowest $\mathrm{p}$ percent of families ranked by income and $\operatorname{GL}(y, p)$ is the generalized Lorenz curve. GL(y,p) is constructed by scaling up the Lorenz curve for $y$, by its mean income level, u, i.e., $G L(y, p)=u L(y, p)$. Only in the case where all nine generalized Lorenz curves, one for each region, are non-intersecting, can we unambiguously rank all of those regions and be confident that our ranking will hold for all non-decreasing Pigou-Dalton welfare functions. It should be noted that $\operatorname{GL}(y, p)>\operatorname{GL}\left(y^{1}, p\right)$ only if $u>u^{\prime}$. Hence for region I to be better off than region $\mathrm{J}$ in terms of all the non-decreaseing PigouDalton welfare measures, it is necessary that mean income is higher in region I than in region J.

Using the data generated above, we construct the generalized Lorenz curves for the nine regions in 1980.
The data for these curves are contained in Table 1. The relative regional rankings are illustrated in Figure 2 by a Hasse diagram. The results can be summarized as follows: for all non-decreasing Pigou-Dalton welfare functions, New England, the East North Central region and the Pacific region are ranked higher than the Middle Atlantic, the West North Central and Mountain regions. These in turn are ranked higher than the South Atlantic and West South Central regions which themselves outrank the East South Central region. Within the various groups of regions no ranking can be established. In other words, the generalized Lorenz of the regions within each of the above groups cross each other but in this case a ranking cannot be specified among the regions within each of these groups unless we are willing to use a specific welfare measure which then implies particular ethical judgements. In what follows we shall examine the relative welfare ranking among regions using some common measures such as the Gini coefficient, (G), Atkinson's family of indexes (A), with the Cobb-Douglas measure (C) as a specific case, and the Theil entropy index (T).

As we have mentioned above, the level of social welfare is the reflection of two factors, the efficiency preference (how high the mean income is) and the equity preference (how equal the income distribution is). We shall first examine the relative ranking of the nine regions in terms of their mean income levels and then in terms of their distributional equality. Of course the latter dependes on the specific index used.

The mean incomes of the nine regions for the year 1980 are shown in Table 2. This table also contains the degree of income equality for each region using the various indexes (G,A,C and T). It should be noted that all the indexes have been normalized such that they have a value of 1.0 for complete equality and are bounded by zero from below. The regional equality rankings for the different indexes are listed in Table 3 along with the regional ranking by mean income. Table 4 shows the welfare levels of the nine regions corresponding to the various indexes. These are simply derived by taking the product of the mean income and the equality index, i.e., $\mathrm{W}=\mathrm{uE}$. The corresponding welfare rankings are listed in Table 5. As expected the relative rankings depend on the specific index used.

It should be pointed out here that once we specify a particular welfare measure, a tradeoff between equality and mean income is possible. A lower mean income in a region can be compensated by a higher degree of equality in that region.

The matrix presented in Figure 3 illustrates the tradeoff between mean income and equality under the Cobb-Douglas index. The rows of this matrix are 
arranged according to the mean income ranking whereas the columns are arranged according to the equality ranking. The entry in the matrix is the welfare ranking. In general, the entries on the top left corner of the matrix are regions that have relatively high mean income levels and more evenly distributed income. Hence they are expected to be ranked relatively high in the welfare comparison. The reverse is true for those entries at the bottom right corner of the matrix. On the other hand, regions that are ranked high in welfare may either be ranked high in both mean income and equality, or ranked high in only one of these. It is instructive to look at the relative welfare ranking of the nine regions from this perspective. Both the East North Central and the Pacific regions have relatively high welfare using the Cobb-Douglas measure. The matrix shows us that the East North Central region has high welfare due to both its high mean income and its relatively even income distribution. On the other hand, income is more unevenly distributed in the Pacific region. However, its mean income level (highest among the nine regions) works to offset this poor distribution.

All the equality indexes are positively associated with the mean income rankings. The rank correlation between these two varies from 0.52 to 0.67 , depending on the index used. The Pacific region, with the poor performance of its equality index, is clearly the most glaring case of inconsistency. Under these circumstances, it is not surprising that the social welfare rankings are quite closely correlated with the mean income rankings. Here the rank correlations range from 0.85 to 0.98 . From these data it is clear that the spread in equality measures is not sizable enough to greatly alter the regional rankings based only on mean incomes.

\section{On The Similarity of Regional Welfare Levels}

Mean income levels vary among the different regions. So do the welfare levels. In this section we are going to develop two indexes. One is a measure of the distribution of regional mean income levels. This measure is closely related to the "between" term of national indexes of inequality (Bourguignon, 1979) The other is a parallel measure of the similarity of regional social welfare levels. In the next section we explore how these indexes have changed over time. The change in these indexes is a natural way to measure the convergence (divergence) in regional mean incomes or social welfare levels.

Consider a population grouped into $\mathrm{m}$ regions. At a particular time each region has a mean income level $\mathrm{u}_{\mathrm{i}}, \mathrm{i}=1, \mathrm{~m}$ and an income distribution $\mathrm{y}_{\mathrm{i}}, \mathrm{i}=1, \mathrm{~m}$. Notice that $y_{i}$ is a vector with $n_{i}$ entries, where $n_{i}$ is the population of region $i$. The income distribution of the entire population is hence $y=\left(y_{1}, \ldots, y_{m}\right)$. The equality index associated with this distribution is $E=E\left(y_{1}, \ldots\right.$, $\left.y_{m}\right)$.

Let us consider the following redistribution of income. For each region $i$, the total income within the region stays the same. However, income is redistributed among the families in each region so that they all have the same income level equal to the group mean income. In essence we eliminate all the intraregional inequality. Now consider the equality index for the nation after the redistribution. We have $B_{u}$, where $\mathrm{B}_{\mathrm{u}}=\mathrm{E}\left(\mathrm{u}_{1}, \ldots, \mathrm{u}_{\mathrm{m}}\right)$. As the intra-regional inequality has been reduced to zero, the index $B_{u}$ merely reflects the difference in mean income levels. $B_{u}$ then is our measure of the degree of equality among regional mean incomes. It indicates how close the regional mean incomes are to each other. In the extreme case where all regions have the same mean income level, $B_{u}=1$. The smaller $B_{\mathfrak{u}}$ is, the wider the spread of regional mean incomes.

What is the value of $B_{u}$ then for the nine regions in the United States in 1980? Using the various indexes we considered in the previous sections, namely the Gini coefficient, the Atkinson's index with the Cobb-Douglas as a special case, and the Theil entropy measure, we construct $\mathbf{B}_{\mathbf{u}}$. The values of $\mathbf{B}_{\mathbf{u}}$ for these various measures are listed in the first row of Table 6. $\mathrm{B}_{\mathrm{u}}$ for the Gini coefficient, for example, is 0.961 . It indicates that the regional mean differentials in 1980 in the United States account for a reduction of equality by 0.039 using the Gini index. A more interesting statement can be made when we construct $\mathrm{B}_{\mathrm{u}}$ for the same index in another year and find out the change in its value over time. The change in the value of $B_{u}$ then indicates whether or not regional mean incomes have moved closer to each other. We shall deal with the question of convergence in the next section. In what follows we are going to construct a corresponding index for the regional welfare variations.

Reconsider the population with $\mathrm{m}$ regions. Now for each region $i$ find its equivalent income $e_{i}$, corresponding to its income distribution $y_{i}$. The equivalent income to $y_{i}$ is defined as that level of income, $e_{i}$, which if given to each family in region $i$ would leave regional welfare unchanged. It is obvious that $\mathrm{e}_{\mathrm{i}}<\mathrm{u}_{\mathrm{i}}$, and the higher the welfare level in region $\mathrm{i}$, the higher its equivalent income. Now consider a hypothetical population in which all families in region $i$ have income $e_{i}$, all families in region $j$ have income $e_{j}$, and so on. The equality associated with this income 
distribution is $B_{w}=E\left(e_{1}, . ., e_{m}\right)$. It is clear that $B_{W}$ measures how close the equivalent incomes and hence the welfare levels of the $m$ regions are to each other. In the extreme case where welfare levels are the same in all regions, $B_{w}$ equals 1 . In general, the greater the dispersion of regional welfare the smaller the value of $B_{w}$.

The specific value of $B_{w}$ depends on the particular index under consideration. Using our data we calculate $B_{W}$ for $G, A, C$ and $T$. Their values in 1980 are listed in Table 6. The value of $B_{w}$ using the Gini coefficient, for example, is $\mathbf{0 . 9 5 4}$. The regional welfare differential among the nine regions therefore causes a reduction of the Gini equality index of 0.0459 . Notice that in this case, as for each of the other indexes, the spread in social welfare is at least as great as the the spread in regional means. In the next section we shall discuss how the values of these indexes have changed from 1950 to 1980 . These changes give us a measure of how much convergence in regional social welfare has taken place.

\section{Patterns Over Time}

If we look back to 1950 we find a somewhat different picture from that described for 1980. In particular, there was a much closer correlation between regional mean family income and regional equality in 1950. The rank correlations for these vary from .83 to .90 depending on which index is used. The major reason for this difference lies in changes in the Pacific ranking on the equality index. In 1950 the Pacific region was ranked either first or second by each of the equality indexes. In 1980 it was ranked sixth by all but one and fifth by that one. One might speculate on the sources of this change. Perhaps it has its roots in the continued expansion of service and high-tech employment. Alternatively, the Pacific region experienced sizable migrations of Hispanics and Southem blacks in the period considered. Whatever the causes, most indexes show the Pacific region's equality essentially unchanged over the 30 years in question. By contrast, all the other regions in the country improve their position.

The result of the improvement in equality in many of the poorer regions (especially the South) and the sluggishness in the Pacific region has been a greater convergence in social welfare than one would anticipate from the movements in mean incomes alone. Table 7 shows the changes in the measures of similarity as applied to regional means and regional welfare levels. In each case the social welfare levels show a greater positive change. For example the convergence in regional means in itself would increase the Gini measure of $B_{u}$ by 4 points. The convergence of regional social welfare implies an increase in $\mathbf{B}_{\mathbf{w}}$ of 6 points.

Perhaps the best way to see the meaning of this convergence in equality indexes for the convergence in social welfare is to compare the actual measure of 1980 social welfare to what it would have been had the equality measure remained unchanged between 1950 and 1980. Using the Cobb-Douglas index, Table 8 presents an example of this calculation for the nine regions. Taking an extreme case, we see that in the East South Central region the social welfare measure would have been $\$ 11,422$ in 1980 in the absence of a change in regional equality. The actual value under this index is $\$ 13,452$, a figure 18 per cent higher. By contrast the table shows that California would have been slightly higher under its 1950 equality index as opposed to its 1980 one. The actual range in social welfare is $\$ 5176$, as opposed to a range of $\$ 7297$ which would have ruled under the older regional distribution.

These observations lead naturally to the question of whether we should now consider the process of convergence in social welfare as essentially complete. The data for 1980 seem to yield values of $B_{w}$ very close to one. However, there are still noticable differences in inequality and regional means. When are the distributions close enough to consider them effectively the same? One way to approach this problem is through the generalized Lorenz curves discussed in earlier. When the curves for two regions cross, we can't make a ranking without specifying a social welfare function. Most of us are reluctant to actually argue for a particular form of such a function. It is not that we differ in our opinions, but rather that as individuals we are unwilling to say one economy is better than another when there are reversals in the generalized Lorenz curves. That is, we balk at a statement that suggests that gains for the middle class are sufficient to offset the losses of the poor or vice versa. We hesitate to rank two curves whose distributions cross.

This argument suggests that the inability to rank income distritutions by means of their generalized Lorenz curves has important qualitative significance. For a set of regions the number of incomparable regions is an index of the similarity of the underlying income distributions.

With nine regions we can make 36 pairwise comparisons. Looking back to the Hasse diagram in Figure 2 we can ascertain that in 1980 there were 29 comparisons that yielded definite rankings and seven that were ambiguous. A similar Hasse diagram for 1950 is presented in Figure 4. Here we see the same 
basic ranking of the Southern and non-Southern regions. The 1950 diagram is not appreciably more complete than the 1980 one. Here there were 30 comparisons that yielded definite rankings and six that were ambiguous. The partial ordinal ranking that we are willing to make in 1980 is about as complete as the one we made in 1950 . While we sense that convergence is in progress, we still do not see the tangle of generalized Lorenz curves which we expect to characterize full convergence. It would seem that interregional convergence has not yet obscured the regional ranking of social welfare.

\section{Conclusions and Directions}

Where regions differ greatly in their degree of equality, it is eminently reasonable that inter-regional comparisons take account of this important fact. The basic approach of this paper encourages consideration of intra-regional equality, without ignoring regional income levels. The argument relies heavily on the theory of social welfare functions and especially the work of Shorrocks (1983). Since equality in the Southem regions of the United States has been considerably worse than elsewhere, the U.S. regional system is an appropriate one for the application of these techniques.

Beyond the question of ranking regions, researchers are concerned with studying the processes of interregional convergence. We suggest that it is useful to view convergence in terms of social welfare levels. This approach is not meant to replace, but rather to supplement the more common use of per capita income convergence. Perhaps the major theoretical contribution of the paper is the construction of $\mathrm{B}_{\mathrm{w}}$, a measure which over time tracks the convergence (or divergence) of welfare levels in a regional system.

At the empirical level our most interesting finding is that social welfare levels among regions have been converging faster than mean incomes. This is largely due to the improved income distributions of the South and the relative persistence of inequality in the Pacific region.

It should be kept in mind that this paper deals only with the problem of measurement. Beyond measurement lies explanation. Existing explanations of intra-regional inequality are rudimentary at best. While there are many models of inter-regional convergence in wages or per capita income, none of these formally consider changes in intra-regional inequality. This is surely an important area for future work.

\section{REFERENCES}

Atkinson, A. (1970) On the Measurement of Inequality, Journal of Economic Theory, pp. 244-63.

Blackorby C., and D. Donaldson (1978) Measures of Relative Inequality and Their Meaning in Terms of Social Welfare. Journal of Economic Theory, pp. 5980.

Bourguignon, F. (1979) Decomposable Income Inequality Measures. Econometrics, pp. 901-920.

Kolm, S. (1976) Unequal Inequalities, I. Journal of Economic Theory, pp. 82-111.

Shorrocks, A. F. (1983) Ranking Income Distributions.

Table 1

Generalize Lorenz Curves for Regions, 1980

\begin{tabular}{|c|c|c|c|c|c|c|c|c|c|c|}
\hline Region & & & & & & & & & & \\
\hline & .10 & .20 & .30 & .40 & .50 & .60 & .70 & .80 & .90 & 1.00 \\
\hline N.B. & 412 & 1305 & 2560 & 4210 & 6139 & 8346 & 10918 & 13845 & 17538 & 23839 \\
\hline M.A. & 346 & 1206 & 2390 & 3993 & 5892 & 8106 & 10681 & 13669 & 17411 & 23824 \\
\hline E.N.C. & 389 & 1312 & 2599 & 4277 & 6331 & 8600 & 11273 & 14309 & 18034 & 24155 \\
\hline W.N.C. & 363 & 1190 & 2387 & 3904 & 5904 & 7774 & 10202 & 13010 & 16445 & 22239 \\
\hline S.A. & 311 & 1057 & 2130 & 3512 & 5116 & 7142 & 9434 & 12179 & 15609 & 21619 \\
\hline E.S.C. & 221 & 833 & 1741 & 2921 & 4371 & 6135 & 8190 & 10719 & 13729 & 18839 \\
\hline w.s.c. & 274 & 972 & 2020 & 3407 & 5061 & 7134 & 9462 & 12273 & 15757 & 21810 \\
\hline Mtn. & 358 & 1192 & 2357 & 3850 & 5672 & 7791 & 10245 & 13085 & 16599 & 22490 \\
\hline Pac. & 388 & 1266 & 2533 & 4131 & 6120 & 8471 & 11120 & 14370 & 18282 & 25279 \\
\hline
\end{tabular}


Table 2

Mean Incomes and Equality Indexes for Regions, 1980

\begin{tabular}{|c|c|c|c|c|c|c|}
\hline & & $\mathbf{E}_{\mathbf{g}}$ & $\mathbf{E}_{\mathrm{a} 1}$ & $\mathbf{E}_{\mathrm{a} 2}$ & $\mathrm{E}_{\mathrm{c}}$ & $\mathrm{E}_{\mathrm{t}}$ \\
\hline N.E. & 23,839 & .637 & .883 & .348 & .760 & .970 \\
\hline M.A. & 23,824 & .624 & .875 & .310 & .740 & .972 \\
\hline E.N.C. & 24,155 & .646 & .888 & .334 & .763 & .986 \\
\hline W.N.C. & 22,239 & .639 & .884 & .338 & .749 & .972 \\
\hline S.A. & 21,618 & .611 & .867 & .300 & .727 & .970 \\
\hline E.S.C. & 18,839 & .608 & .864 & .274 & .714 & .967 \\
\hline W.S.C. & 21,811 & .606 & .863 & .280 & .716 & .968 \\
\hline Mtn. & 22,490 & .635 & .882 & .333 & .755 & .970 \\
\hline Pac. & 25,279 & .617 & .871 & .317 & .737 & .970 \\
\hline
\end{tabular}

Table 3

Rankings for Mean Incomes and Equality Indexes for Regions, 1980 u

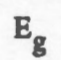

$\begin{array}{ll}\text { N.E. } & 3 \\ \text { M.A. } & 4 \\ \text { E.N.C. } & 2 \\ \text { W.N.C. } & 6 \\ \text { S.A. } & 8 \\ \text { E.S.C. } & 9 \\ \text { W.S.C. } & 7 \\ \text { Mtn. } & 5 \\ \text { Pac. } & 1\end{array}$

$\mathbf{E}_{\mathbf{g}}$

5

1

2

7

8

9

4

6
Equality Indexes

$\mathbf{E}_{\mathbf{a} 1}$

$\mathrm{E}_{\mathrm{a} 2}$

$\mathbf{E}_{\mathrm{c}}$

$E_{t}$

3

Equality Indexes

$\begin{array}{llll}3 & 1 & 2 & 4 \\ 5 & 6 & 5 & 3 \\ 1 & 3 & 1 & 1 \\ 2 & 2 & 3 & 2 \\ 7 & 7 & 7 & 5 \\ 8 & 9 & 9 & 9 \\ 9 & 8 & 8 & 8 \\ 4 & 4 & 4 & 7 \\ 6 & 5 & 6 & 6\end{array}$


Table 4

Welfare measures for Regions, 1980

\begin{tabular}{lccccc}
\hline Region & \multicolumn{5}{c}{ Welfare Index } \\
& $\mathrm{W}_{\mathrm{g}}$ & $\mathrm{W}_{\mathrm{a} 1}$ & $\mathrm{~W}_{\mathrm{a} 2}$ & $\mathrm{~W}_{\mathrm{c}}$ & $\mathrm{W}_{\mathrm{t}}$ \\
N.E. & 15,178 & 21,061 & 8,290 & 18,123 & 23,131 \\
M.A. & 14,871 & 20,839 & 7,337 & 17,631 & 23,160 \\
E.N.C. & 15,607 & 21,449 & 8,081 & 18,437 & 23,573 \\
W.N.C. & 14,204 & 19,667 & 7,523 & 16,875 & 21,621 \\
S.A. & 13,214 & 18,746 & 6,481 & 15,721 & 20,976 \\
E.S.C. & 11,459 & 16,282 & 5,161 & 13,452 & 18,224 \\
W.S.C. & 13,223 & 18,820 & 6,105 & 15,615 & 21,114 \\
Mtn. & 14,276 & 19,845 & 7,488 & 16,978 & 21,819 \\
Pac. & 15,592 & 22,016 & 8,009 & 18,628 & 24,527 \\
\hline
\end{tabular}

Table 5

Welfare Rankings for Regions, 1980

\begin{tabular}{|c|c|c|c|c|c|}
\hline \multirow[t]{2}{*}{ Region } & \multicolumn{3}{|c|}{ Welfare Index } & \multirow[b]{2}{*}{$\mathrm{w}_{\mathrm{c}}$} & \multirow[b]{2}{*}{$w_{t}$} \\
\hline & $w_{g}$ & $\mathrm{w}_{\mathrm{a} 1}$ & $\mathrm{w}_{\mathrm{a} 2}$ & & \\
\hline N.E. & 3 & 3 & 1 & 3 & 4 \\
\hline M.A. & 4 & 4 & 6 & 4 & 3 \\
\hline E.N.C. & 1 & 2 & 2 & 2 & 2 \\
\hline w.N.C. & 6 & 6 & 4 & 6 & 6 \\
\hline S.A. & 8 & 8 & 7 & 7 & 8 \\
\hline E.S.C. & 9 & 9 & 9 & 9 & 9 \\
\hline W.s.c. & 7 & 7 & 8 & 8 & 7 \\
\hline Mtn. & 5 & 5 & 5 & 5 & 5 \\
\hline Pac. & 2 & 1 & 3 & 1 & 1 \\
\hline
\end{tabular}


Table 6

Indexes for Dispersion of Regional Mean Incomes and

Regional Welfares, 1980

\begin{tabular}{cccccc}
\hline & $G$ & $A_{1}$ & $A_{2}$ & $C$ & $T$ \\
$B_{u}$ & .961 & .999 & .994 & .997 & 1.000 \\
$B_{w}$ & .954 & .998 & .983 & .996 & 1.000 \\
\hline
\end{tabular}

Table 7

Changes in $B_{u}$ and $B_{w}$ 1950-1980

\begin{tabular}{cccccc}
\hline & G & A1 & A2 & C & T \\
$\mathrm{B}_{\mathrm{u}}$ & +.039 & +.005 & +.019 & +.009 & +.001 \\
$\mathrm{~B}_{\mathrm{w}}$ & +.060 & +.006 & +.069 & +.020 & +.001 \\
\hline
\end{tabular}

Table 8

Regional Welfare Levels 1980 using the Cobb-Douglas Index

\begin{tabular}{lrrr}
\hline Region & \multicolumn{1}{c}{$u$} & \multicolumn{1}{c}{$\mathrm{u}^{80} \mathrm{E}^{80}$} & \multicolumn{1}{c}{$\mathrm{u}^{80} \mathrm{E}^{50}$} \\
N.E. & $\$ 23,839$ & $\$ 18,123$ & $\$ 17,633$ \\
M.A. & 23,824 & 17,631 & 17,413 \\
E.N.C. & 24,155 & 18,437 & 17,853 \\
W.N.C. & 22,239 & 16,875 & 15,432 \\
S.A. & 21,618 & 15,721 & 13,931 \\
E.S.C. & 18,839 & 13,452 & 11,422 \\
W.S.C. & 21,811 & 15,615 & 13,726 \\
Mtn. & 22,490 & 16,978 & 15,878 \\
Pac. & 25,279 & 18,628 & 18,719 \\
\hline
\end{tabular}


FIGURE 1:

THE RELATION BETWEEN THE LORENZ CURVE AND THE GENERALIZED LORENZ CURVE

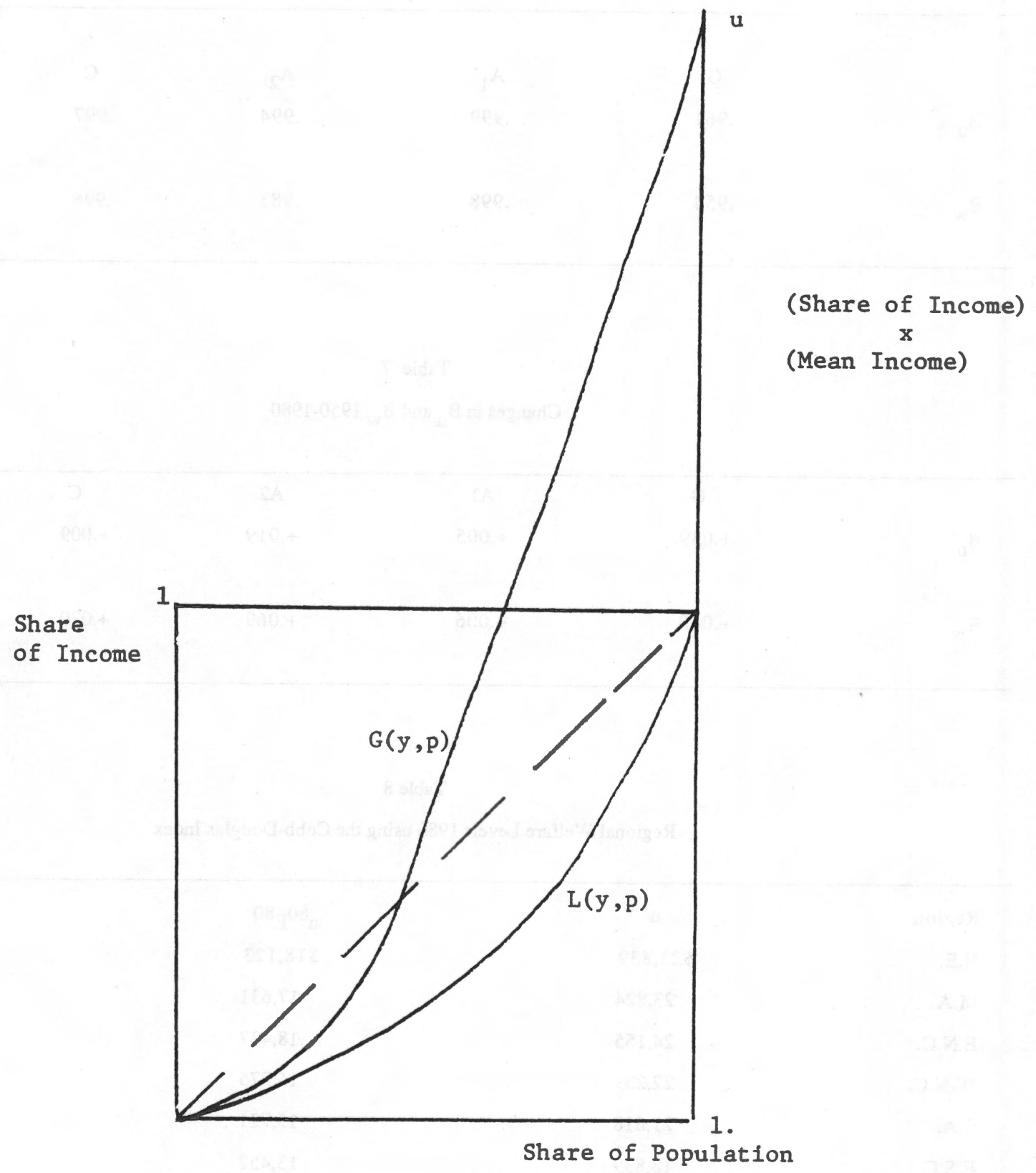

Based on Shorrocks (1983). 
FIGURE 2:

GENERALIZED LORENZ CURVE RANKING, 1980

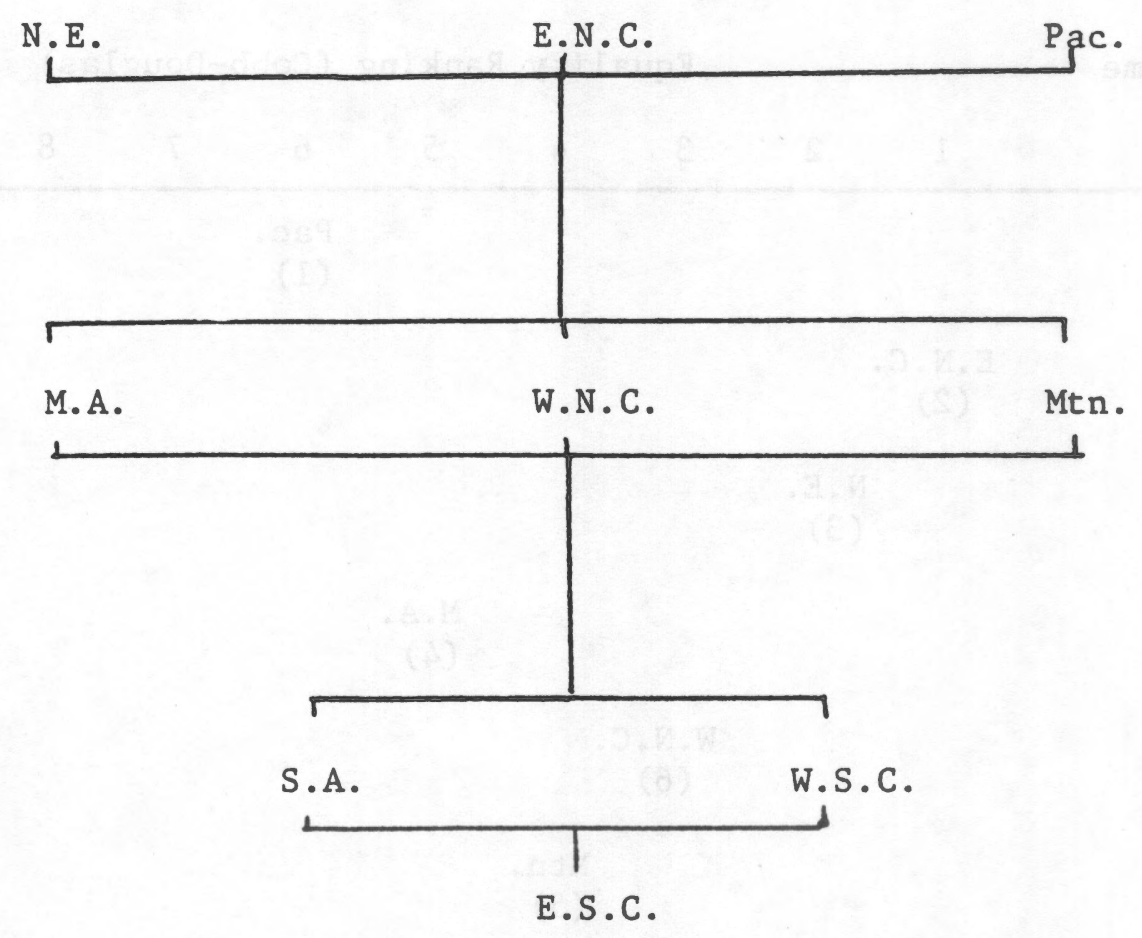

Note: Regions with a higher position in the diagram dominate all regions connected to them by a downward flowing line. 
FIGURE 3:

THE RELATION BETWEEN MEAN INCOME AND EQUALITY IN DETERMINING SOCIAL WELFARE

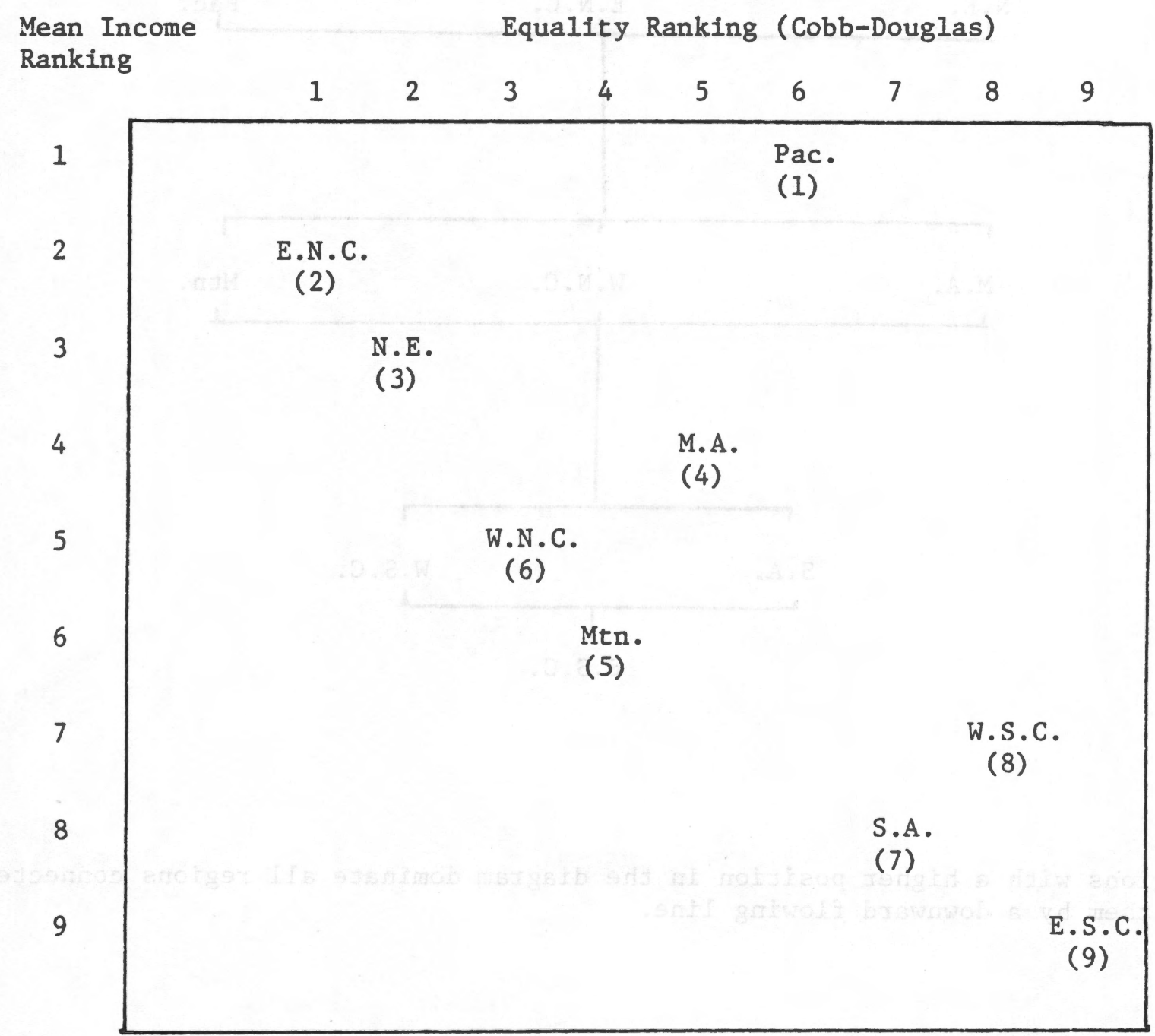

The ranking in parentheses below each region is its ranking in terms of the Cobb-Douglas social welfare function. 
FIGURE 4:

GENERALIZED LORENZ CURVE RANKING, 1950
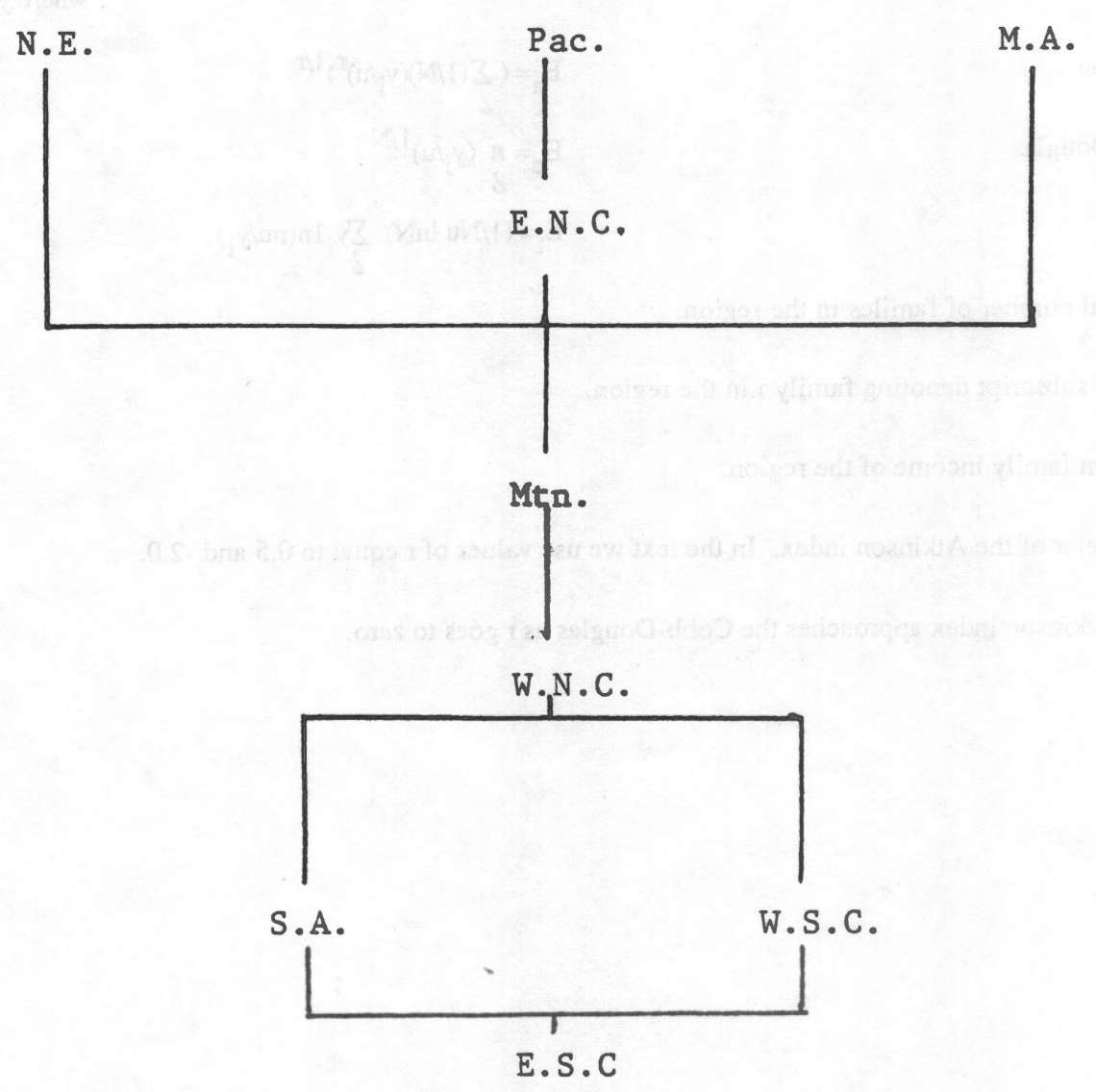

Note: Regions with a higher position in the diagram dominate all regions connected to them by a downward flowing line. 
APPENDIX

Table A-1

Formulas for Equality Indexes

1. Gini

$$
E_{g}=-(1 / N)+(2 / N u)\left(y_{1}+2 y_{2}+\ldots+N y_{N}\right),
$$

where $y_{1} \geq y_{2} \geq \ldots \geq y_{N}$.

2. Atkinson

3. Cobb-Douglas

$\mathrm{E}_{\mathrm{a}}=\left(\sum_{i}(1 / \mathrm{N})\left(\mathrm{y}_{\mathrm{i}} / \mathrm{h}\right)^{\mathrm{r}}\right)^{1 / \mathrm{r}}$

$\mathrm{E}_{\mathrm{c}}=\pi\left(\mathrm{y}_{\mathrm{i}} / \mathrm{u}\right)^{1 / \mathrm{N}}$

4. Theil

$\mathrm{E}_{\mathrm{t}}=(1 / \mathrm{Nu} \ln \mathrm{N}) \sum_{i} \mathrm{y}_{\mathrm{i}} \ln \left(n u / \mathrm{y}_{\mathrm{i}}\right)$

$\mathrm{N}$ is the total number of familes in the region.

$\mathrm{i}=1, \mathrm{~N}$ is the subscript denoting family $\mathrm{i}$ in the region.

$\mathrm{u}$ is the mean family income of the region.

$\mathrm{r}$ is a parameter of the Atkinson index. In the text we use values of $\mathrm{r}$ equal to 0.5 and -2.0 .

Note: the Atkinson index approaches the Cobb-Douglas as r goes to zero. 